\title{
Coma decimal y punto
}

\section{Decimal point and point}

Señor editor:

Hemos podido observar que se usa -en algunas de las publicaciones científicas, así como en documentos técnicos escritos por profesionales de nuestro país- la coma y el punto decimal indistintamente en las expresiones numéricas y/o unidades de medida, inclusive en una misma comunicación. Esta ausencia de uniformidad afecta la claridad y precisión de la información que se transmite en la comunidad científica internacional. ${ }^{1}$ Por eso, es conveniente ver con detenimiento no solo la estructura del manuscrito, sino también el empleo de las palabras, los números, las siglas, los signos y otros elementos que les dan forma, antes de enviarlos a una revista médica. Muchos hemos aprendido a distinguir entre lo que es correcto y lo que convencionalmente se acepta en estas publicaciones médicas, aunque algunas veces puede ser incorrecto para otras: por ejemplo, escribir $\mathrm{mg} / \mathrm{dL}$ y no $\mathrm{mg} / \mathrm{dl}$, como lo sugiere el Sistema Internacional de Unidades (SI). ${ }^{2}$

El Sistema Internacional de Unidades (SI) nació en 1960, en la undécima conferencia de la Convención Métrica. El nuevo sistema de medidas inicialmente se basaba en seis unidades básicas (metro, kilogramo, segundo, amperio, kelvin y candela), a las que se añadió en 1971 el mol. ${ }^{3}$ En abril de 1977, la Organización Mundial de la Salud (OMS) insta a la comunidad internacional a usar el SI. ${ }^{4,5}$ Sin embargo, la adopción del sistema ha sido irregular por las peculiaridades de algunos países, especialmente Estados Unidos de América y Reino Unido (The New England Journal of Medicine renunció en 1992 a obligar al empleo del SI en los artículos presentados para la publicación en su revista). ${ }^{5}$ Esto ocasionó una interrupción en la tendencia internacional a usar este sistema de medida. Sin embargo, las recomendaciones de la OMS en esta materia siguen estando plenamente vigentes, por lo que conviene conocerlas y emplearlas en todos los artículos biomédicos. ${ }^{3}$

El Sistema Legal de Unidades de Medida del Perú (Slump), aprobado por Ley $23560,{ }^{6}$ tiene como base e incluye en toda su estructura $\mathrm{al} \mathrm{SI}^{7}$ y es el Instituto Nacional de Defensa de la Competencia y de la Protección de la Propiedad Intelectual (Indecopi), a través del Servicio Nacional de Metrología, la autoridad en Perú en cuestiones sobre la materia. ${ }^{8}$

El SI no solo establece y define el conjunto de unidades a utilizar y las relaciones entre ellas, sino que también da reglas fijas acerca de cómo deben escribirse los resultados de las mediciones y qué habrá de tenerse en cuenta en la redacción de un texto científico. No cumplirlas originará un texto final que podría ser inadmisible o incomprensible para el lector. A pesar de ello, en los textos científicos y médicos en español, no es infrecuente encontrar numerosos errores y vacilaciones en la escritura de las unidades de medida, más aun cuando en el entorno científico internacional la recomendación unánime es a favor del uso del SI y, en la mayoría de los países del mundo, constituye el conjunto legal de unidades. ${ }^{4}$

Estas son algunas de las reglas para la escritura científica haciendo uso del SI:7,9,10

- Cuando se escribe un valor numérico entero, no es necesario escribir la coma decimal ni los 
ceros a su derecha (siempre y cuando esos ceros no sean cifras significativas). Es decir, se puede escribir 7427 en lugar de 7427,0 (si el cero de la parte decimal no es una cifra no significativa).

- Los valores numéricos que solo contienen parte decimal deben escribirse con un cero, que es indicativo de que no tienen parte entera; a continuación se escribe la coma (marcador decimal) y enseguida la parte decimal.

- No debe suprimirse el cero y no debe indicarse la parte decimal colocando solamente la coma a la izquierda del valor numérico.

- Para escribir los valores numéricos, se deben utilizar las cifras arábigas y la numeración decimal y separar la parte entera de la decimal mediante una coma (,).

- No debe utilizarse el punto para separar enteros de decimales.

- Para facilitar la lectura de los valores numéricos, se recomienda escribirlos separados en grupos de tres cifras contados a partir de la coma decimal hacia la izquierda y derecha, separados mediante un espacio en blanco. Este puede omitirse si la parte entera o decimal del valor numérico no tiene más de cuatro cifras o cuando se expresan años como parte de una fecha o no. Sin embargo, existen excepciones en la aplicación de esta regla, pero que no competen al ámbito científico.

- Cuando se escriban valores numéricos en columnas, la coma decimal debe estar alineada en una sola columna.

- Cuando se escriben valores numéricos en serie, estos deben separarse entre sí con punto y coma, seguido de un espacio.

- El valor numérico siempre precede a la unidad y está separado de ella por un espacio, a excepción de los grados, minutos y segundos de los ángulos planos, en que no se deja espacio.

Si bien el SI establece que se puede usar la coma o el punto para la separación de números decimales, ${ }^{10}$ en Perú se ha establecido que la coma será usada como único marcador para separar la parte entera de la decimal. ${ }^{7}$

Es necesario remarcar que este sistema constituye uno de los factores principales para lograr la racionalización, sistematización, simplificación y adecuado desarrollo de las actividades educativas, comerciales, científicas y tecnológicas en el Perú. ${ }^{11}$ En ese sentido, es importante que nos detengamos a revisar la redacción de nuestras propuestas de publicación para evitar algunos de los errores descritos y cumplir con el marco legal vigente sobre la materia.

\section{REFERENCIAS BIBLIOGRÁFICAS}

I. Beltrán R. Terminología farmacéutica. Rev Centro Inv (Méx). 2000;4(I4):77-82.

2. Vega L. Algunas omisiones, usos y abusos de palabras, siglas y abreviaciones, en manuscritos sometidos a publicación. Rev Mex Pediatr. 2003;70(4):|159-6I.

3. Castedo J, Sánchez-Gómez LM, Rodríguez-Sainz C, Ramos L. Estándares científico-técnicos en las publicaciones relacionadas con las ciencias de la salud. Radiología. 1998;40(10):687-92.

4. Hellín J. El Sistema Internacional de Unidades: aspectos prácticos para la escritura de textos en el ámbito de las ciencias de la salud. Panace@ [Internet]. 2004 [citado 7 ago 20|4];5(I7-|8):200-7. Disponible en: http://www.medtrad.org/panacea/IndiceGeneral/ nl7-18_tradyterm-Hellin.pdf

5. Campion EW. A retreat from SI units. N Engl J Med. 1992;327(I):49.

6. República del Perú. Ley $N^{\circ} 23560$, Sistema Legal de Unidades de Medida del Perú (promulgado el 31 de diciembre de 1982) [Internet]. Lima, Perú: El Peruano; 1982 [citado 7 ago 2014]. Disponible en: http://www.inacal.gob.pe/inacal/files/metrologia/ LEYES/Ley_23560.pdf

7. República del Perú. Decreto Supremo $N^{\circ}$ 064-84-ITI/IND (promulgado el 5 de diciembre de 1984) [Internet]. Lima, Perú: El Peruano; 1984 [citado 7 ago 20 I4]. Disponible en: http://www. inacal.gob.pe/inacal/files/metrologia/LEYES/DS_064_84_ITIIND.pdf

8. República del Perú. Decreto Supremo $N^{\circ} 024-93$ Itinci, Encomiendan el Servicio Nacional de Metrología al Indecopi (promulgado el 24 de setiembre de 1993) [Internet]. Lima, Perú: El Peruano; 1993 [citado 7 ago 2014]. Disponible en: http://www. inacal.gob.pe/inacal/files/metrologia/LEYES/DS_024_93_Itinci. pdf

9. Dajes-Castro J. Sistema Internacional de Unidades de Medida [Internet]. Lima, Perú: Fondo Editorial del Congreso de la República; 1999 [citado 7 ago 20I4]. Disponible en:

10. Bureau International des Poids et Mesures (BIPM). The International System of Units (SI). 8th ed. Paris: STEDI Media; 2006; updated in 2014 [citado 7 ago 20I4]. Disponible en: http:// www.bipm.org/en/publications/si-brochure/

II. Indecopi. El Sistema Legal de Unidades de Medida del Perú [Internet]. Lima, Perú: Indecopi; [citado 7 ago 20l4]. Disponible en: http://archive-pe.com/page/3274773/2013-1206/http://www.indecopi.gob.pe/0/modulos/JER/JER_Interna. aspx?ARE=0\&PFL=|3\&JER=347

\section{Alfredo Enrique Oyola-García}

Médico. Investigación en Ciencias Naturales y Sociales. aoyola@redmed-ica.com

Fecha de recepción: 29 de abril de 2015

Fecha de aceptación: 30 de junio de 2015 